\title{
Inquietações, reflexões e provocações sobre o "texto e o contexto" do turismo em escala planetária
}

\section{Uneasiness, thoughts and challenges related to the "text and context" of tourism on a global scale}

\author{
Kerlei Eniele Sonaglio (SONAGLIO, K. E.) ${ }^{*}$
}

RESUMO - Este artigo foi elaborado a partir de inquietações, reflexões e provocações da presente autora sobre o "texto e o contexto" do turismo em escala planetária. A intenção é a de suscitar entre os pares acadêmicos o debate e a investigação sobre a produção do conhecimento em turismo realizados, compartilhados e originados nos (e a partir dos) "mundos ocidental e oriental". Para tal, as ideias estão apoiadas em publicações clássicas na área e também nos diálogos ocorridos entre os participantes do XI Seminário da Associação Nacional de Pesquisa e Pós-Graduação em Turismo ANPTUR 2014, realizado em Fortaleza/CE (Brasil). Assim, entendeu-se haver predominância e influência dos estudos de autores europeus no que se conhece e se produz em turismo. Além disso, salienta-se a necessidade, e algumas razões, para se conhecer os estudos orientais sobre o turismo.

Palavras-chave: Teoria do turismo; História do turismo; Conhecimento em turismo; Turismo no Ocidente; Turismo no Oriente.

ABSTRACT - This opinion article is a product of present author about uneasiness, thoughts and challenges related to the "text and context" of tourism on a global scale. It aims to arouse, among academic peers, debates and research on the production of knowledge in tourism, shared and originated in (and from) "eastern and western worlds". Therefore, the ideas here exposed are based upon classic publications in the area and dialogues that occurred among participants of the $2014^{\text {th }}$ ANPTUR XI Seminar. It is understood that there is a supremacy and influence of European authors in what is known and produced in the area of tourism. It also emphasizes the need and a few reasons why it is important to learn oriental studies on tourism.

Key words: Theory of tourism; History of tourism; Knowledge in tourism; Western tourism; Eastern tourism.

\footnotetext{
* Formação: Graduação em Turismo pelas Faculdades Integradas Associação de Ensino de Santa Catarina (FASSESC), Especialização em Turismo Empreendedor, Mestrado e Doutorado em Engenharia Ambiental pela Universidade Federal de Santa Catarina (UFSC). Atividade profissional: Professora da Universidade Federal do Rio Grande do Norte (UFRN) nos cursos de Graduação, Mestrado e Doutorado em Turismo. E-mail: kerlei@ufrnet.br
} 


\section{INQUIETAÇÕES DE UMA JOVEM PROFESSORA}

Foram dois “Thomas” (O Kuhn e o Cook) que suscitaram, em 2002, uma sucessão de inquietações sobre os estudos turísticos para uma jovem professora que se lançava à docência no ensino superior em Turismo. Era tempo de reunir as principais publicações sobre Turismo disponíveis nas bibliotecas das instituições de ensino superior brasileiras e de vasculhar o que fosse possível encontrar nos 7 anos de funcionamento da internet para o público (dadas as limitações próprias do período). Era preciso compreender a história (e origens) do turismo e seus conceitos! Era preciso unificar os conteúdos em ordem cronológica (e lógica) porque era necessário dar contexto ao texto para iniciar os trabalhos na disciplina intitulada "Teoria Geral do Turismo".

Neste período, a professora iniciava seu doutoramento na Universidade Federal de Santa Catarina - UFSC e o contato com as obras de Kuhn (2001), Nicolescu (1999) e Morin (1977, 1984, 1991, 1992a, 1992b, 1992c) a despertavam para a compreensão contextual, histórica e paradigmática da ciência e para o olhar complexo e transdisciplinar sobre os objetos em estudo. Assim, foi inevitável: a) o esforço empreendido na tentativa de se compreender as fases paradigmáticas do turismo, o contexto em que foram erigidas e como se deu sua evolução; b) o "olhar transdisciplinar para o turismo". Entretanto, a maioria das obras sobre turismo reforçava o olhar calcado nas abordagens positivista, funcionalista ou sistêmico para o turismo (em caráter multi ou interdisciplinar).

Então na procura pelas obras da área do turismo destacaram-se os valorosos clássicos internacionais e nacionais disponíveis e consultados à época: Fuster (1978), Acerenza (1984), Jafari (1994), Tribe (1997; 1999), Wahab (1977), Krippendorf (1977; 2000), Urry (1991; 1995), Molina (1991), Boullón (2000), De La Torre (1994), Beni (2001), Rejowski (2002), Trigo (1993; 1995), Ruschmann (1997), Barretto (1996), Moesch (2000) - (só para citar alguns). E neles se encontraram citações de Schattenhofen, Hunziker e Krapf (tidos como alguns dos primeiros a explicar/conceituar "turismo"). Entretanto, na busca pela "linha do tempo" dos estudos sobre o turismo e pelos "marcos" históricos desde seus primórdios, era evidente a ausência de informações e/ou as dissenções e similitudes interpretativas entre os autores, bem como 
também entre eles e o disposto na obra Introdução ao Turismo da Organização Mundial do Turismo - OMT (2001).

As divergências e semelhanças estavam relacionadas, principalmente, aos conceitos de turismo e seu vínculo "visceral" com o campo estatístico e econômico; o debate epistemológico; a questão da sua cientificidade. Outros debates figuravam considerando a perspectiva histórica de sua origem que, não raro, estava atrelada ao comportamento pré-histórico dos deslocamentos humanos para a sobrevivência, de nomadismo; e depois, relacionado às conquistas territoriais e participação dos cidadãos nas primeiras olimpíadas que se tem registro na história ocidental (com o uso das tabernas, estalagens e hospedarias). Outros autores relacionavam o turismo com as questões migratórias temporárias ou então os deslocamentos temporários na fase précapitalista e a fase do capitalismo industrial (como as Grandes Navegações, o Grand Tour e o Petit Tour), e, por fim, com a motivação do entretenimento, descanso, férias, eventos e negócios (citando apenas os principais).

Como marco/surgimento do turismo moderno, a maioria dos autores afirmava ter ocorrido com a Revolução Industrial, na Europa, em fins do século 18 e início do século 19. Já outros compreendiam que o turismo nasceu e se desenvolveu na fase do capitalismo monopolista-financeiro, especialmente após a Segunda Guerra Mundial, donde julgavam ter iniciado o turismo massificado.

No entanto, mais recentemente, Santos Filho (2008) realizou sua crítica a estes posicionamentos sobre a origem do turismo e explica que a categoria "turismo" é resultado do desenvolvimento de um processo histórico e, portanto sua existência aparece sob diferentes tonalidades e em períodos diversos por meio de manifestações consideradas travestidas em outras categorias que, na verdade, são expressões derivadas do turismo. Isto é, aproximações de um todo mais desenvolvido. Assim, com esse entendimento, o autor considera que o turismo não pode ser compreendido como sendo algo que aparece de repente como aqueles que acreditam que esse fenômeno surge com o Capitalismo e na Inglaterra. Para ele, o turismo sempre esteve presente na realidade social, porém, sua manifestação durante a história da humanidade surge à luz de diferentes e aproximadas essencialidades. Com esse pressuposto claro da existência do fenômeno turístico na história da humanidade, a nação que estiver com os meios de 
produção mais desenvolvidos consegue produzir um "Thomas Cook" que revolucionou na prática e organizou o então chamado turismo moderno.

No mosaico de opiniões e tentativas de esclarecer as origens, trajetória e as bases teórico-conceituais do turismo (desde 2002), estavam os "dois Thomas" desta professora, suscitando em sua mente questionamentos distintos, porém igualmente importantes.

Assim, por meio deste texto opinativo, reflexivo e provocativo a professora em questão (e que assina este artigo) apresentará suas inquietações e reflexões sobre os estudos turísticos, suscitadas pelos dois "Thomas" e amplificadas após a sua participação no XI Seminário Anual da Associação Nacional de Pesquisa e PósGraduação em Turismo 2014, realizado em Fortaleza/CE. O evento reuniu diversos célebres pesquisadores, professores e estudantes brasileiros (e alguns convidados estrangeiros) que se empenharam em debater sobre a transversalidade na qualificação e competitividade em turismo.

É oportuno reiterar e esclarecer que o propósito deste texto é o de lançar reflexões e provocações, não havendo o compromisso estrito em explicar, detalhar e/ou fundamentar as questões sobre a teoria e epistemologia do turismo ou mesmo sobre a sua práxis.

\section{O PRIMEIRO “THOMAS": O COOK (1808 - 1892)}

O inglês Thomas Cook (1808-1892) era um vendedor de bíblias (SANTOS FILHO, 2008).

Como mencionado por autores como Fuster (1978), Acerenza (1984) e Rejowski et al (2002), Cook é tido como o "pai do turismo moderno" por ter sido considerado o primeiro a organizar/operar uma viagem para um grupo de pessoas. Foi em 1841, quando alugou um trem, comprou e revendeu passagens para transportar 570 indivíduos que participariam de um encontro contra o alcoolismo em Leicester. Este fato o consagrou como o primeiro agente de viagens, já que realizou a primeira viagem em grupo em larga escala de modo organizado. Cook aperfeiçoou, anos depois, a operacionalização das viagens incluindo outros serviços (além do transporte), como 
hospedagem e tours, dando origem aos primeiros "pacotes turísticos". Deste modo, muitos autores consideram este episódio como sendo o ingresso do turismo na era industrial.

\section{O SEGUNDO "THOMAS": O KUHN (1922 - 1996)}

Thomas Kuhn (1922-1996) foi um cientista estadunidense! (KUHN, 2001). Foi um pesquisador Graduado, Mestre e Doutor em Física e Filósofo da Ciência que apresentou e explicou o contraste entre a concepção formal e controlada da ciência (chamada de perspectiva formalista) e a concepção contextual histórica, donde defende que a ciência se dá ao longo do tempo e, portanto, possui características peculiares próprias de cada época. (KUHN, 2001). Assim, Kuhn mostra que os aspectos históricos, sociológicos e psicológicos são relevantes para fundamentar a ciência e compreender sua evolução.

Kuhn refletiu sobre a invisibilidade das revoluções que estão (ou não) registradas nos manuais científicos e explicou que a característica dos manuais é a de:

[...] conterem apenas um pouco de história, seja um capítulo introdutório, seja, como acontece mais frequentemente, em referências dispersas aos grandes heróis de uma época anterior. Através dessas referências, tanto os estudantes como os profissionais sentem-se participando de uma longa tradição histórica. (KUHN, 2001, p. 175).

Para o autor, isto ocorre mesmo que os estudantes e profissionais desconheçam (ou apenas reproduzam parcialmente) boa parte dos textos e contextos paradigmáticos e dos "saltos paradigmáticos" que marcaram uma determinada época.

Nesta perspectiva histórica, a noção kuhniana de paradigma caracteriza a chamada "ciência normal" (com seus problemas, teorias e métodos compartilhados e aceitos pela comunidade científica) e ele explica que a ciência se desenvolve considerando as seguintes fases: a fase pré-paradigmática; a ciência normal (acumulação de conhecimento); a crise; as revoluções científicas (os saltos científicos emergência de outro paradigma); a nova ciência normal; a nova crise; novas revoluções. 


\section{OS QUESTIONAMENTOS}

Muitas inquietações suscitadas pelos "dois Thomas" e complexificadas pelos estudos em Morin (1977, 1984, 1992a, 1992b, 1992c, 1996), ainda estão se fazendo presentes na mente da professora. E elas aumentam, se acumulam e parecem a confinar, por vezes, no espectro limitado da "ciência normal" do turismo ocidental e seu quebracabeças irresoluto! Pois bem, mas o turismo não é ciência, dizem muitos autores! Obviamente o propósito deste texto opinativo e provocativo não é o de debater esta questão, afinal, o problema são as inquietações provocadas pelos “dois Thomas”!

Desta forma, então:

- Se é preciso compreender o contexto sócio-econômico-cultural em que os saberes são produzidos ao longo do tempo;

- Se há relevância no papel da história "na e da" ciência para as pessoas acessarem os conhecimentos e seus contextos;

- Se é preciso compreender que os "manuais" científicos informam, sobretudo, sobre os debates científicos vencedores e compartilhados pelos pares nos períodos paradigmáticos; raramente informam sobre os textos e contextos que permeavam as discussões e foram descartadas no período, seja por qualquer razão (daí a reprodução sistemática do conhecimento fragmentado);

- Se é preciso transdisciplinar e complexificar os estudos e práticas no âmbito do turismo;

Então, é preciso revisitar o que tem sido publicado sobre o Turismo desde o ocidente (especialmente do continente europeu) e refletir sobre seus textos e contextos na intenção de se compreender como o conhecimento turístico foi produzido e reproduzido. Além disso, é preciso conhecer e compreender como o conhecimento turístico foi (e está) sendo produzido em outras regiões do Planeta, como por exemplo, nos países orientais.

Assim, considerando a divisão geopolítica do Planeta Terra (Ásia, África, América, Europa, Oceania, Oriente Médio, Polar e Oceanos) e, sobretudo, as questões relacionadas à cultura ocidental e oriental (no sentido sociopolítico e cultural, o que inclui, por exemplo, a Nova Zelândia e a Austrália no cenário ocidental!), emerge um primeiro e básico questionamento propulsado pelos "dois Thomas" e que representa e 
simboliza, para a professora, a evidência da fragilidade em que certos estudos turísticos estão apoiados (como fragilidades históricas, conceituais e metodológicas):

Mas será que foi Thomas Cook o "pai do agenciamento moderno"?

Esta indagação partiu da necessidade de se compreender como os "marcos históricos" relacionados ao turismo (e suas veracidades) foram sendo compartilhados e replicados na academia. Então, eis que Santos Filho (2008, p. 16-17) realiza um estudo sobre Thomas Cook e o publica na Revista TURyDES e que, de certa maneira, tal estudo se coaduna com as reflexões que a professora vinha realizando. Nesta publicação de 2008, o autor destaca 2 aspectos importantes:

1 - Parte da literatura editada em português existente que faz menção ao personagem Thomas Cook, aparece por meio de pequenos comentários nos inúmeros livros editados, muitas vezes em forma de nota e com um conjunto de informações repetitivas sem qualquer reflexão que não seja a mera descrição dos dados biográficos desse personagem. Com raras exceções existem obras que caracterizam historicamente Cook ensaiando indagações procedentes. Mesmo com o perigo de cometer alguns equívocos involuntários, podemos destacar algumas obras de autores brasileiros; a) Turismo no Percurso do Tempo. Organizado por Mirian Rejowski; b) História das Viagens e do Turismo de Ycarim Melgaço Barbosa; c) Manual de iniciação ao turismo de Margarita Barretto; d) Aspectos Multidisciplinares da História e Turismo de Haroldo Leitão Camargo. In. Como aprender e como ensinar.

2 - A literatura referente à histórica do processo de industrialização da Inglaterra traduzida para o português na qual tive acesso entre as quais as obras do historiador de Eric J. Hobsbawm, Paul Mantoux, Frédéric Mauro, William Otto Henderson (...). Não mencionam nem de forma secundária o nome de Thomas Cook, mesmo quando escrevem sobre o desenvolvimento do transporte ferroviário inglês, essa ausência pode significar duas hipóteses; A primeira àquela que considerava que o direito ao lazer e turismo estava reservado a uma nobreza já decadente, porém ainda portadora de recursos financeiros e a uma forte burguesia que se encostava ao estilo de vida aristocrata; A segunda, por Thomas Cook ser um pastor batista que desenvolvia um trabalho de recuperação a alcoólicos ter ousado a programar viagens para as classes sociais populares em localidades tidas como redutos exclusivos dos ricos.

Na referida publicação, o autor defende que a história do turismo mundial foi escrita por meio de uma lógica determinada no interior das relações de produção que vão privilegiar o Estado Inglês que naquele momento invadia o mundo com sua produção de mercadorias, por ser o mais emergente economicamente naquele período

\footnotetext{
${ }^{1}$ Esclarecendo a questão do período: Cook é considerado pai do "agenciamento moderno". No entanto, seria mais apropriado mencionar "pai do agenciamento contemporâneo" porque os estudos turísticos, majoritariamente, partem de indivíduos ocidentais e no mundo cultural ocidental a Contemporaneidade inicia com a Revolução Francesa em 1789 e a primeira viagem agenciada de Cook ocorreu em 1841!
} 
histórico e gerando um domínio imperialista do saber universal no campo do turismo. Assim, se transmitiam os conhecimentos tidos como verdadeiros segundo $o$ desenvolvimento das relações de produção e das forças produtivas que expressavam o desenvolvimento econômico e social daquele país para o mundo.

Mas Santos Filho (2008) admite o valor contemporâneo de Thomas Cook e seu papel no desenvolvimento do turismo num determinado momento da história, entretanto rejeita a tentativa da historiografia inglesa em conjunto com parte da historiografia brasileira de supervalorizar esse personagem como se o fenômeno do turismo fosse natural da Inglaterra.

Assim, concorda-se com o referido autor, pois sob este olhar, se coloca a história do turismo planetário desprovida de qualquer sinalização que não seja a eurocêntrica e, na verdade, acaba-se por se submeter a adotar a leitura da história do turismo (nacional e internacional) segundo ideias dominantes do "colonizador". Neste sentido, Cisne e Gastal (2010, p. 1) rediscutem as periodizações da História do Turismo admitindo que elas "tem sido feitas por meio de recortes temporais escolhidos a partir das convenções adotadas pelos autores que contextualizam o Turismo no Tempo".

No entanto, é preciso considerar que partindo de um olhar positivista e compreendendo o turismo enquanto um setor da economia que estrutura-se visando uma função específica no mercado mundial, então, seria lógico entender a via do marco capitalista como originária de um turismo moderno e contemporâneo. Além disso, sob esta lógica, é compreensível que se desprezem as tentativas de explicar um turismo que tivesse ocorrido antes do advento do capitalismo. Mas, mesmo sob a ótica do turismo propulsado pela revolução industrial, é preciso complexificar o "olhar" sobre os episódios que supostamente deram origem ao agenciamento vigente.

Assim, dando continuidade à reflexão sobre as origens do agenciamento e a questão histórica sobre o turismo, principalmente sobre os episódios associados ao desenvolvimento e estruturação dos transportes (já que o marco associado à Cook refere-se ao turismo ferroviário), de Grand Tour e Petit Tour (associado às viagens educacionais), se pode refletir sobre os deslocamentos e comportamentos humanos no Oriente (já registrados pela História). A partir disso, poder-se-ia imaginar que na antiguidade com a Rota da Seda, por exemplo, o Oriente já dispunha de estrutura para transporte (terrestre e aquaviário) que possibilitava o trasladado de inúmeros indivíduos 
e mercadorias no próprio Oriente e entre Oriente e Europa. Após a descontinuação da Rota (já na Idade Média), os europeus acessaram as Índias e a China passando pela África, por uma nova rota marítima. Estes deslocamentos propiciaram importantes intercâmbios artísticos, culturais, comerciais, intelectuais e tecnológicos.

Outrossim, o pai da economia moderna, Adam Smith, escreveu em 1776 na sua obra "A riqueza das nações" o seguinte: A China foi por um bom tempo uma das mais ricas, isto é, uma das mais férteis, melhor cultivadas, mais industrializadas e mais populosas nações do mundo. Dá a impressão, porém, de estar muito tempo imutável. Marco Polo, que a visitou há mais de quinhentos anos atrás, descreveu seus modos de produção agrícola, sua característica industrial e a abundância populacional de modo similar como é descrita por viajantes nos tempos atuais. (O'ROURKE, 2008).

Então, se pode imaginar a possibilidade de ter havido, muito antes do agenciamento de Cook ou mesmo dos já citados Grands e Petits Tours europeus, viagens de estudo e/ou viagens organizadas no próprio território Oriental. Vale salientar que no país mais populoso do mundo, a China, por exemplo, a primeira Universidade (HUNAN UNIVERSITY, 2014) foi fundada em 976 d.C., ou seja, antes do período em que a Europa fundava, em 1150 d.C., a Universidade de Paris (primeira Universidade da Europa). As universidades medievais e as que se sucederam, foram importantes instituições que promoveram, além da produção do saber, diversas revoluções e intercâmbios culturais que ainda perduram.

Portanto, em se tratando da questão educacional e acadêmica, é certo que existem escolas e universidades no Ocidente e no Oriente há séculos. Porém, a questão é que aquilo que os ocidentais (ou mesmo alguns orientais com formação em escolas de cultura ocidentais) estudam e publicam sobre turismo tem influenciado e composto o escopo central do saber em turismo no Brasil. Exemplo disso são os trabalhos publicados em língua inglesa (principalmente em periódicos do Ocidente) por diversos autores originários da China e Japão (publicações no Annals of Tourism Research, Tourism Management, International Journal of Hospitality Management). A maioria das publicações versa sobre a questão do comportamento do consumidor, sobre a imagem de destinos turísticos ou sobre os produtos e recursos turísticos, como mencionado por Cardona (2014). 
E, considerando "Oriente",2 e "Ocidente", sucedem outros questionamentos:

Mas, o que pensam e publicam sobre o turismo os pesquisadores de cultura oriental, especialmente aqueles que publicam em seu idioma pátrio? Quais seus textos e contextos sobre esta questão? Desde quando eles estudam o turismo? Quais suas bases teórico-epistemológicas? Qual a história do turismo no Oriente? Quem são seus precursores/sucessores e que autores os influenciaram e influenciam nos seus estudos sobre turismo? Quais os mais antigos autores/pesquisadores orientais (sobre turismo) que se tem notícia? O que escreviam? Quais foram os enfoques teórico-metodológicos dos primeiros autores orientais que escreveram sobre o turismo? Desde quando e onde estão publicados os textos clássicos dos autores orientais que não escreveram em inglês ou espanhol? Houve tradução? Para que idiomas?

Quais relações complexas permeiam o turismo no Oriente para os orientais? Como (e sob que lógica) o turismo interno se desenvolveu e se desenvolve? Como esclarecem, interpretam e planejam o seu turismo interno? Quais as motivações e o comportamento dos mais variados "tipos de turistas" do oriente? Como são definidas (e como se desdobram) as políticas públicas de turismo na China, Japão, Coréia do Sul e do Norte, Mongólia, Índia, Nepal, Vietnã, Israel, Afeganistão, Irã, Turquia, Kwait, Emirados Árabes Unidos, Arábia Saudita, Rússia (oriental) (etc.)?

A lógica funcionalista, sistêmica, positivista ou fenomenológica faz parte dos estudos turísticos no Oriente? Quais estudos turísticos foram realizados diante da lógica socialista ou comunista? E o capitalismo e a globalização, capitalizaram e globalizaram o saber turístico no Oriente? A partir de quando e de que maneira? Como se deu este processo no percurso do tempo (parafraseando Rejowski, 2002)? Quais saberes (acumulados ou recém-descobertos) pelos orientais se poderia compartilhar?

Mas e agora? Que conhecimento histórico, teórico, epistemológico e metodológico sobre o turismo foi acumulado e (re)produzido no ocidente?

É certo e inegável que se produziu saber! Basta ler as obras de autores consagrados no turismo (e já citados no início deste texto)! São conteúdos significativos e fundamentais para a academia do turismo. Porém é preciso densificar e ampliar este conhecimento, principalmente porque está sendo produzido um saber originado desde a Europa Ocidental! Então se indaga: Que problemas e soluções "foram importados"

\footnotetext{
${ }^{2}$ Por questões socioculturais e políticas, entende-se "Oriente" pela divisão geopolítica mundial (Ásia Central/Oriental/Setentrional/Meridional/Sudeste/Sudoeste e Oriente Médio).
} 
deste conhecimento fractal ocidental? E na sequencia, como foram tratados e/ou transformados? E o que foi "exportado"? Eles estão solucionando as deficiências no "quebra-cabeças" do turismo brasileiro? Há originalidade nas produções brasileiras sobre o turismo? Quais são elas?

É provável que muitas destas indagações já possuam respostas contundentes e esclarecedoras, ou então podem se mostrar desnecessárias. Entretanto é justo que se precise compartilhar e historicizar o conhecimento em turismo (guardadas as suas restrições e limitações, é claro). A história ajuda a "contextualizar" os acontecimentos e compreender sua evolução e transformação (e/ou saltos paradigmáticos). É uma tarefa incrivelmente árdua, necessária e infindável no processo do conhecimento. Portanto, ainda que já se tenham saberes memoráveis em turismo no Ocidente, considera-se que há um longo caminho a percorrer!

\section{CONSIDERAÇÕES FINAIS}

Certamente que se reúnem estas e outras inquietações desde 2002! A presente autora enquanto professora começou a passar por inquietudes ao identificar que havia lido pela primeira vez o livro de Thomas Kuhn (A estrutura das revoluções científicas) em 2001 e compreendeu: que o contexto histórico e sociológico no qual emerge a ciência é fundamental no processo da sua evolução/transformação; compreendeu que os paradigmas vigentes, muitas vezes, condicionam as pessoas a permanecer no conforto de suas amarras que são compartilhadas pelos pares na academia; descobriu que estava usando exclusivamente "os óculos do ocidente" ao olhar para o turismo.

Foi em 2002, na busca pela história do turismo que o segundo Thomas proporcionou o "start" perturbador. Foi a ruptura paradigmática mais elementar! A professora percebeu que não havia estudado e tampouco lido sobre a história do turismo no mundo (no sentido da totalidade do Planeta), como muitas obras de autores clássicos apresentam ou mesmo descrevem os autores mais recentes, como por exemplo, Panosso Netto (2012)! Ela deu-se conta que leu sobre a história do turismo na Europa Ocidental (é o que consta na maioria das publicações sobre o turismo). Leu e lê sobre teorias e metodologias que partem, principalmente, de autores da Europa, América e Oceania. 
Logicamente que estando o Brasil no Ocidente, são compartilhados diversos padrões ocidentais econômicos e socioculturais. Assim, é possível afirmar que certos contextos em que se produzem os saberem turísticos também são compartilhados. Mas o melindroso e caótico cenário turístico que está posto, revela a sua incompletude teórica, metodológica, estrutural, locacional e relacional. Mostra a fragilidade social, acadêmica, estatal e privada na condução e responsabilidades sobre a concepção, operacionalização e dinamização do setor produtivo e/ou impactados pelo turismo.

O futuro do turismo que envolve distintas motivações, deslocamento, permanência por certo período de tempo, uso de serviços de hospedagem e alimentação e ausência de realização de atividade remunerada no destino, talvez, esteja seriamente comprometido se regido por outra lógica paradigmática.

O turismo é uma "prática social", mas tem sido enquadrado como um "setor da economia"! Obviamente que a perspectiva econômica está inclusa na operacionalização e dinâmica do turismo, no entanto ela precede e mantem-se em privilégio na maioria dos debates sobre o turismo. Isto porque a sociedade mundial está mergulhada na "rodaviva" do sistema econômico capitalista e mudanças na "prática social do turismo" implicariam, primeiro, em transformações da tessitura social contemporânea.

Sob esta ótica, outras compreensões do movimento turístico que antecederam o marco capitalista poderiam estar sendo exploradas.

As Tecnologias da Informação e Comunicação já sinalizam mudanças significativas na sociedade. A variável "deslocamento" poderá sucumbir rapidamente dos textos e contextos turísticos, assim como, por consequência, poderão sucumbir certos padrões usuais de turismo. Além disso, as novas tecnologias certamente auxiliarão no acesso (e possibilidade de leitura) às publicações sobre o turismo em idiomas menos divulgados e menos lidos no Ocidente (como mandarim, japonês, coreano, mongol, russo, híndi e árabe) e vice-versa, já que se constata haver uma lógica dogmática que privilegia e reforça a predominância de publicações dos textos em inglês nos mais variados campos científicos. Assim, ao se ampliar o espectro e o alcance dos diferentes olhares e diferentes pesquisas sobre o turismo no mundo, quiçá poder-se-á encontrar estudos diametralmente opostos aos que as pessoas estão acostumadas a produzir e a reproduzir, porque podem estar (ou provocar novos estudos) regidos por lógicas radicalmente diferentes. 
Por isso que Santos Filho (2008) já fazia o alerta que a intenção de se proceder a uma leitura ontológica do fenômeno turístico exige o aporte de uma análise fora dos padrões hegemônicos existentes. O procedimento para avançar na teoria do conhecimento é o respeito que se tem que ter a outros enfoques epistemológicos que fundamentam a existência de uma academia progressista, produtiva, democrática que deve sempre resguardar a busca incansável de fatos científicos com profundo grau de tolerância diante de outras epistemes, pois é esse procedimento que traz o conhecimento cientifico.

Mas, voltando ao cerne deste texto opinativo a fim de tecer as considerações finais, a questão é: Sabe-se o que é turismo? É realmente conhecida a história do turismo no planeta Terra? As pessoas estão ou não estão mergulhadas no mar profundo e escuro de um paradigma de turismo que as mantém confortáveis, mas que necessita dar seu "salto paradigmático" (parafraseando Kuhn)?

Talvez os debates acadêmicos mais profícuos sejam suscitados durante e após as reuniões dos estudiosos do turismo em eventos específicos da área. Este texto, por exemplo, fluiu após a participação da autora (enquanto professora) no XI Seminário Anual da Associação Nacional de Pesquisa e Pós-Graduação em Turismo 2014, ocorrido em Fortaleza/CE.

Sob o tema da transversalidade no turismo, as conferências de abertura e encerramento (Marcelino Nechar e Scott Cohen, respectivamente), as mesas temáticas, os GTs, as confraternizações e os encontros informais entre os pares proporcionaram sinais evidentes da necessidade de: adensamento teórico-metodológico nos estudos sobre turismo; estudos epistemológicos críticos em turismo; posturas transdisciplinares e olhar complexo na produção do conhecimento em turismo e na sua práxis; e, por fim, transversalizar o turismo; descobrir o que o mundo Ocidental e Oriental já conheceram e conhecem sobre o turismo e suas implicações.

Desde o referido Seminário e considerando os "paradigmas", "crises", "rupturas" e "saltos" defendidos por Kuhn no processo da ciência (muito embora o turismo não possua o status de ciência), não seria ilegítimo pensar que se está falando uma língua chamada "euroturismo" (citado na palestra do Scott Cohen); que saberes fragmentados sobre o turismo estão sendo compartilhados; que não se conhece a história 
global/planetária do turismo; sabe-se pouco, mas as pessoas se comportam como se soubessem muito (e a verdade) sobre o turismo!

Ainda bem que Kuhn (2001) deixou evidente sua crítica ao argumento positivista de que a ciência progride, inexoravelmente, em direção à verdade! Para ele, não se trata de um progresso em si, mas da existência de uma sequencia histórica de revoluções científicas no modo de pensar do indivíduo cognoscente, na emergência de novos paradigmas, de novas visões de mundo. Assim, as revoluções científicas são explicadas como episódios de desenvolvimento não-cumulativo, nos quais um paradigma mais antigo é total ou parcialmente substituído por um novo, incompatível com o anterior.

E eis que se tem a boa nova de que há muito a ser realizado em termos acadêmicos no turismo e para o turismo!

A professora em questão (e que assina este texto opinativo), até o momento, concorda com Kuhn. Além disso, concorda com o ensinamento de Platão que suscita algumas importantes reflexões: "A parte que ignoramos é muito maior que tudo quanto sabemos.”.

\section{REFERÊNCIAS}

ACERENZA, M. Administración del turismo: conceptualización y organización. México: Trillas, 1984.

BARRETTO, M. Manual de iniciação ao estudo do turismo. Campinas: Papirus, 1996.

BENI, M. C. Análise estrutural do turismo. São Paulo: SENAC, 2001.

BOULLÓN, R. C. Planificación del espacio turistico. Mexico: Trillas, 2000.

CARDONA, J. R. Imagen que poseen los españoles de China como destino turístico. Revista Turismo e Sociedade, Curitiba, v. 7, n. 2, p. 292-307, abril de 2014.

CISNE, R., GASTAL, S. Turismo e sua história: rediscutindo periodizações. Anais do VI SEMINTUR - Seminário de Pesquisa em Turismo do Mercosul / Saberes e Fazeres no Turismo: Interfaces. Realizado de 9 e 10/072010. UCS: Caxias do Sul/RS. Disponível em: 
<http://www.ucs.br/ucs/tplVSeminTur\%20/eventos/seminarios_semintur/semin_tur_6/g t09/arquivos/09/Turismo\%20e\%20sua\%20historia.pdf >. Acesso em: 20/08/2015.

FUSTER, L. F. Teoria y tecnica del turismo. Madrid: Nacional, 1978. V. I e II.

HUNAN UNIVERSITY. History. Disponível em: <http://wwwen.hnu.edu.cn/About\%20HNU/History/>. Acesso em: 07/10/2014.

JAFARI, J. La cientifización del turismo. Estudios y Perspectivas del Turismo, 3. ed. Argentina: CIET, 1994.

KRIPPENDORF, J. Sociologia do turismo: para uma nova compreensão do lazer e das viagens. São Paulo: Aleph, 2000.

Les devoreurs de paysages. Lousanne: Edition 24 Heures, 1977.

KUHN, T. S. A estrutura das revoluções científicas. São Paulo: Perspectiva, 2001.

MAFFESOLI, M. Sobre o nomadismo. Rio de Janeiro: Record, 2001.

MOESH, M. A produção do saber turístico. São Paulo: Contexto, 2000.

MOLINA, S. Conceptualización del turismo. México DF: Limusa, 1991.

MORIN, E. Ciência com Consciência. Portugal/Lisboa: Publicações Europa-América, 1984.

Cultura de massas no século XX: o espírito do tempo. Rio de Janeiro: Forense Universitária, 1977.

O método vol. 1: A natureza da natureza. Portugal/Lisboa: Publicações Europa-América, 1991.

O método vol. 2: A vida da vida. Portugal/Lisboa: Publicações EuropaAmérica, 1992a.

O método vol. 3: O conhecimento do conhecimento. Portugal/Lisboa: Publicações Europa-América, 1992b. 1992c.

O método vol. 4: As ideias. Portugal/Lisboa: Publicações Europa-América,

O problema epistemológico da complexidade. Portugal/Lisboa: Publicações Europa-América, 1996.

NICOLESCU, B. O manifesto da transdisciplinaridade. São Paulo: TRIOM, 1999. 
OMT, Organização Mundial do Turismo. Introdução ao turismo. São Paulo: Ed. Rocca, 2001.

O'ROURKE, P. J. A riqueza das nações de Adam Smith: uma biografia. Rio de Janeiro: Jorge Zahar Ed., 2008.

PANOSSO NETTO, A. O que é turismo. São Paulo: Brasiliense, 2012.

REJOWKI, M. Desenvolvimento do Turismo moderno. In: REJOWSKI, M; YASOSHIMA, J. R.; STIGLIANO, B. V.; SILVEIRA, A. S. Turismo no percurso do tempo. São Paulo: Aleph, 2002.

REJOWSKI, M. Turismo e pesquisa científica. Campinas/SP: Papirus, 1996.

RUSCHMANN, D. van de M. Turismo e planejamento sustentável: a proteção do meio ambiente. São Paulo: Papirus, 1997.

SANTOS FILHO, J. Thomas Cook: Marco da Historiografia Dominante no Turismo. Revista de Investigación en Turismo y Desarrollo Local (TURyDES), Málaga/Espanha, v. 1, n. 2, 2008.

TORRE, O. de la. El turismo fenômeno social. México DF: Fondo de Cultura Economica, 1994.

TRIBE, J. Economía del ocio y el turismo. Madrid: Sistesis, 1999. 657, 1997.

The indiscipline of tourism. Annals of tourism research, v. 24, n. 4, p. 638-

TRIGO, L. G. G. Turismo básico. São Paulo: SENAC, 1995.

.Turismo e qualidade: tendências contemporâneas. São Paulo: Papirus, 1993.

URRY, J. Consuming places. London: Lancaster University, 1995.

O olhar do turista: lazer e viagens nas sociedades contemporâneas. São Paulo: Studio Nobre/SESC, 1991.

WAHAB, S. E. A. Introdução à administração do turismo. São Paulo: Pioneira, 1977. 